\section{Pacific Northwest}

\section{National Laboratory}

Operated by Battelle for the

U.S. Department of Energy

\title{
Distributed Energy Resources, Power Quality and Reliability - Background
}

\author{
L. A. Schienbein \\ J. G. DeSteese
}

January 2002

Prepared for the

U.S. Department of Energy

Office of Power Technologies

Office of Distributed Resources

under Contract DE-AC06-76RL01830

Prepared for the U.S. Department of Energy

under Contract DE-AC06-76RL01830 


\title{
DISCLAIMER
}

This report was prepared as an account of work sponsored by an agency of the United States Government. Neither the United States Government nor any agency thereof, nor Battelle Memorial Institute, nor any of their employees, makes any warranty, express or implied, or assumes any legal liability or responsibility for the accuracy, completeness, or usefulness of any information, apparatus, product, or process disclosed, or represents that its use would not infringe privately owned rights. Reference herein to any specific commercial product, process, or service by trade name, trademark, manufacturer, or otherwise does not necessarily constitute or imply its endorsement, recommendation, or favoring by the United States Government or any agency thereof, or Battelle Memorial Institute. The views and opinions of authors expressed herein do not necessarily state or reflect those of the United States Government or any agency thereof.

\section{PACIFIC NORTHWEST NATIONAL LABORATORY operated by \\ BATTELLE for the UNITED STATES DEPARTMENT OF ENERGY under Contract DE-AC06-76RLO 1830}

\author{
Printed in the United States of America \\ Available to DOE and DOE contractors from the \\ Office of Scientific and Technical Information, \\ P.O. Box 62, Oak Ridge, TN 37831; \\ Ph: (865) 576-8401 \\ Fax: (865) 576-5728 \\ Email: reports@adonis-osti.gov
}

\author{
Available to the public from the National Technical Information Service, \\ U.S. Department of Commerce, 5285 Port Royal Rd., Springfield, VA 22161 \\ Ph: (800) 553-6847 \\ Fax: (703) 605-6900 \\ Email: orders@ntis-fedworld.gov \\ Online ordering: http://www.ntis.gov/ordering.htm

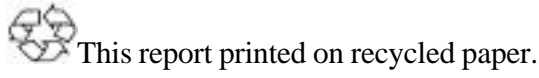

$(8 / 00)$ 
Distributed Energy Resources, Power Quality and Reliability - Background

Lawrence A. Schienbein

John G. DeSteese

January 2002

Prepared for the

U.S. Department of Energy

Office of Power Technologies

Office of Distributed Resources

Under Contract DE-AC06-76RL01830 



\section{Summary}

Power quality $[\mathrm{PQ}]$ and power reliability $[\mathrm{PR}]$ gained importance in the industrialized world as the pace of installing sensitive appliances and other electrical loads by utility customers accelerated, beginning in the mid-1980s. Utility grid connected customers rapidly discovered that this equipment was increasingly sensitive to various abnormalities in the electricity supply. Fundamentally, electrical load devices containing high-speed digital processors and power electronic components are more sensitive to power fluctuations that can be tolerated by less sophisticated and commonplace loads such as light bulbs, refrigerators, and water heaters.

Electricity consumers using these sensitive devices, or manufacturing high-value products using processes depending on these devices, have typically installed some form of uninterruptible power supply [UPS] as a solution to power system problems, and/or bought insurance to reduce their vulnerabilities to PQ and PR problems. However, both new technologies and changes in utility system organization and operations may provide a number of better solutions. The concurrent trend to a utility infrastructure containing distributed energy resources [DER] (also called distributed generation [DG]), energy storage systems and central control may offer future relief from grid-transmitted and facility-caused disturbances. The financial impacts of less than adequate power quality and reliability and the consequent demand for solutions, coupled with the unique characteristics of distributed energy resources, offer an opportunity for more rapid deployment of DER as primary and/or backup power supplies. DER has the potential to overcome utility and site-specific supply problems and to help compensate for other developing limitations of the existing distribution grid.

This report introduces the power quality and power reliability problems, the main concepts and features of today's electric power grid, the overall characteristics and development status of the various DER technologies, and the main features and effects of power quality and reliability. It also addresses the key issues involved in assessing the ability of DER technologies to enhance the quality of the power delivered to the customer and to improve the reliability of the electric power supply system. 



\section{CONTENTS}

SUMMARY

iii

1.0 INTRODUCTION AND BACKGROUND

1.1 THE ELECTRIC GRID AND THE PROBLEMS OF POWER QUALITY AND POWER RELIABILITY 4

1.2 DEFINITION OF POWER QUALITY AND POWER RELIABILITY 4

1.3 RELEVANT STANDARDS 5

1.4 DER TECHNOLOGIES, CHARACTERISTICS AND OPERATING CONFIGURATIONS

1.5 OVERVIEW OF DER TECHNOLOGIES AND DEPLOYMENT 6

1.6 ENERGY TECHNOLOGY DEVELOPMENT AND MARKETS FOR DER, POWER QUALITY AND RELIABILITY 8

1.6.1 Markets 9

1.6.2 Market Applications 9

$\begin{array}{ll}\text { 1.6.3 Power Quality Markets for DER } & 10\end{array}$

$\begin{array}{lll}1.7 & \text { PURPOSE OF THE PROJECT }\end{array}$

2.0 THE CONVENTIONAL POWER TRANSMISSION AND DISTRIBUTION $\begin{array}{ll}\text { SYSTEM } & 13\end{array}$

$\begin{array}{lll}2.1 & \text { FUNCTION } & 13\end{array}$

2.2 STRUCTURE OF THE TRANSMISSION AND DISTRIBUTION SYSTEM 13

2.3 NETWORK OPERATION CONSIDERATIONS 15

3.0 POWER QUALITY TERMS AND DEFINITIONS 17

3.1 POWER QUALITY DISTURBANCES 17

$\begin{array}{lll}3.1 .1 & \text { Outage } & 18\end{array}$

3.1.2 Voltage Sag 18

3.1.3 Voltage Swell 18

3.1.4 Harmonic Distortion 18

3.1.5 Commutation Notches 20

3.1.6 Frequency Deviations 21

3.1.7 Surges 22

3.1.8 Electrical Noise 22

3.2 EXAMPLE OF POTENTIAL POWER QUALITY IMPACTS 22 
4.0 UTILITY CONTROL OF POWER QUALITY 25

4.1 VOLTAGE REGULATION 25

4.2 FREQUENCY REGULATION 25

4.3 CONTROL OF WAVEFORM DISTORTION 26

5.0 CUSTOMER CONTROL OF POWER QUALITY AND RELIABILITY 27

$\begin{array}{lll}5.1 & \text { EQUIPMENT ADDITIONS } & 27\end{array}$

5.2 IN-FACILITY DISTRIBUTION SYSTEM INTEGRITY 27

6.0 POWER QUALITY SOLUTIONS 29

6.1 PROTECTION STRATEGIES AND PLANNING 29

6.2 PQ TOLERANT EQUIPMENT 30

$\begin{array}{lll}6.3 & \text { TRANSIENT PROTECTION }\end{array}$

6.4 PROTECTION AGAINST PERSISTENT PHENOMENA 31

6.5 POWER QUALITY AND POWER RELIABILITY MANAGEMENT IN THE FUTURE

7.0 CONCLUSIONS 33

8.0 REFERENCES 35

APPENDIX A: AN OVERVIEW OF DC TO AC ELECTRIC POWER

CONVERTERS $\quad$ A-1 


\section{FIGURES}

1. Claims Experience Of A Major Insurer Resulting From Power Quality and Reliability Problems

2. Power Quality And Reliability Disturbance Versus Available Mitigating Technologies 3

3. Schematic Of The Conventional Grid System 14

4. Principal Categories Of Poor Power Quality 17

5. Distortion Resulting From Imposition Of Harmonics 19

6. System-Wide Frequency Deviation Caused By 1200-Mw Generation Loss 21

7. Loads And Disturbance Sources On Adjacent Feeders 22

8. Representative Distribution Of 100 Consecutive PQ Events 29 



\subsection{Introduction and Background}

This report is an account of work conducted by Pacific Northwest National Laboratory [PNNL] for the U.S. Department of Energy [DOE] Office of Power Technologies [OPT] to assess the power quality [PQ] and power reliability [PR] implications of distributed energy resources [DER].

The purpose of this document is to introduce the main concepts and features of today's electric power grid, the overall characteristics and development status of various DER technologies, the main features and effects of power quality and reliability, and the principal issues to be addressed in other project tasks. Hence, the intent of this report is to lay the foundation for understanding, interpreting and assessing the results of ongoing work, which will be described and discussed in subsequent project reports.

\subsection{The Electric Grid and the Problems of Power Quality and Reliability}

Billed as one of the greatest engineering achievements of the 20th century, the vast network of large electric power generating plants ("central stations") and transmission and distribution [T\&D] systems (collectively often called the power "grid") has made reliable electric power a key feature of our society. The prospect of life without reliable and high quality electric power is unimaginable in the developed areas of the world.

This system delivers alternating current $[\mathrm{AC}]$ electrical power to consumers at a constant frequency of 60 cycles per second $[\mathrm{Hz}]$ in North America, and regulated voltage. Pure AC power is characterized by sinusoidal voltage and current waveforms (the sinusoid is defined by an exact mathematical expression). These waveforms are produced and absorbed naturally by rotating electric machines and offer advantages in power transmission, such as the ability to easily and efficiently transform power to high voltages for transmission and distribution and then to much lower voltages for consumption by end-use devices (or "loads").

Since the beginning of the electric age, electrical equipment has been built to tolerate a considerable range of voltage, frequency, and waveform variability. In addition, utilities have employed controls and system maintenance procedures to achieve standards of both PQ and PR (or "availability") that have been generally acceptable. That system of generation, T\&D, and loads worked well until the 1980s when the demand for more electricity, electricity of higher quality, and higher supply reliability accelerated sharply. The accelerating demand shift to electrical energy is demonstrated by the fact that since the 1970s, electricity in the industrialized nations has grown from $25 \%$ of total end-use energy consumption to more than $37 \%$ in 2000 . By 2025, electrical demand is forecast to account for more than $50 \%$ of total energy use (Yeager, 2001). This growth in demand for both the quantity of electricity and for higher quality/higher reliability electricity has not always been matched by a correspondingly increased investment in generating capacity or in T\&D facilities capable of meeting these demands.

The reliability and quality of the electric power delivered in the United States seems to have deteriorated in the last 5 years. One reason for this deterioration appears to be the transition of the utility industry from a regulated monopoly to a less regulated, free market infrastructure. The result has been a change from centralized planning, operation and control of the electric utility network, and its associated power reliability and quality, to decentralized operation of the various parts of the network by many participants with different goals. Another reason is the escalating sensitivity of sophisticated loads. In short, the levels of supply reliability and power quality that were, on average, "good enough" as late as the early 
1990s are now causing problems to a growing number of consumers. Circumstantial evidence of the cost of inadequate supply and quality of electric power abounds in journal and newspaper articles. Firmer evidence is available from insurers of commercial business, who are experiencing increasing claims related to power supply problems (Figure 1 shows the experience of a major industry insurer).

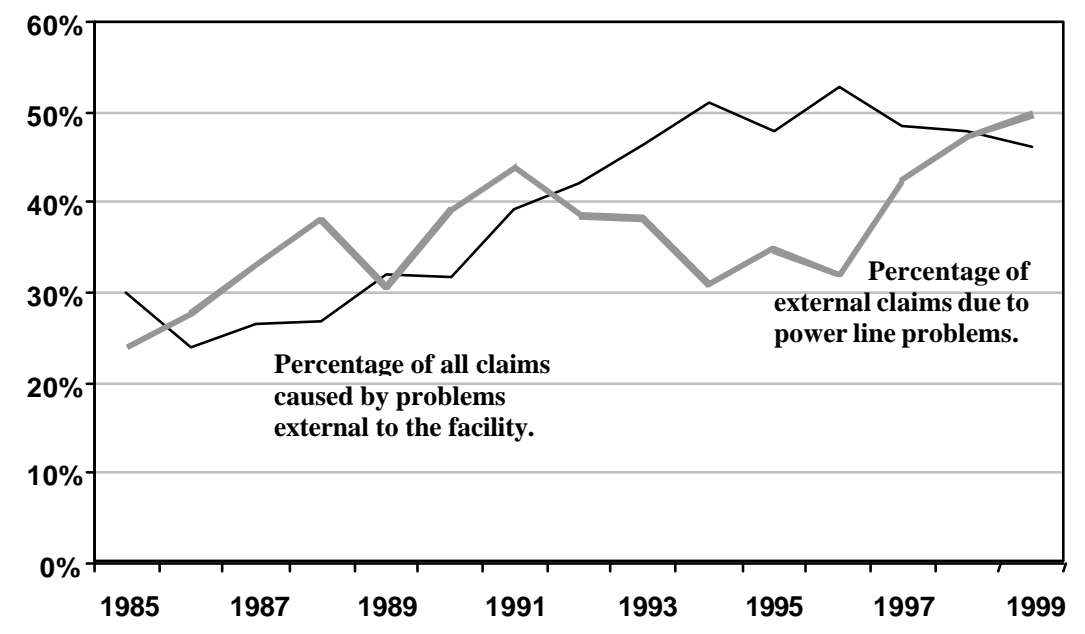

Figure 1. Claims Experience of a Major Insurer Resulting from Power Quality and Reliability Problems

The consumer cost of poor PQ has escalated by orders of magnitude over the last 2 decades. For example, in the early 1980s, a supply interruption was estimated by the Institute of Electrical and Electronic Engineers [IEEE] to cost industries with less than 1000-kW peak demand an average of $\$ 4.59 / \mathrm{kW}$ and $\$ 8.11 / \mathrm{kWh}$ (IEEE Gold Book, 1980). Thus, about 20 years ago, the loss of $10 \mathrm{~kW}$ for 30 minutes would be valued at only $\$ 86.45$. Estimates of average outage cost for this consumer class in the most recent issue of this reference (IEEE Gold Book, 1997) escalated to $\$ 12.51 / \mathrm{kW}$ and $\$ 15.03 / \mathrm{kWh}$. The corresponding estimated average cost of such a supply interruption had increased to about $\$ 200$ in the mid-1990s. This is still in sharp contrast with, and appears to remarkably underestimate, the extraordinarily high cost of poor PQ experienced by today's high technology users. If this trend is not reversed, commercial claims may eventually lead to prohibitive insurance premiums for losses related to power system problems.

Higher quality and reliability are demanded as the result of the introduction and proliferation of more sensitive electric devices (seen as loads), such as personal computers and factory process equipment controllers that use high-speed digital processors and power electronic devices. Brown (1998) notes that, as of about 1998, consumer electronics accounted for about $10 \%$ of the electric load in the United States, and its share of the total demand was growing rapidly. Furthermore manufacturing automation, based on mid-power "smart" power electronics, is also growing rapidly. This demand is largely driven by the fact that approximately 50 to $60 \%$ of the electric energy in the United States is consumed by motors (Brown, 1998). Equipment of this kind is more sensitive to relatively small quality variations in the power supply and, in some circumstances, also generates harmonics and other PQ problems that affect nearby electrical loads. Brief interruptions that are tolerated in an analog network can lead to more costly and prolonged outages in high-speed digital networks.

Customers using these sensitive devices, or manufacturing high-value products using processes depending on these devices, have typically installed some form of uninterruptible power supply [UPS] as 
a solution to power system problems and/or bought insurance to reduce their vulnerabilities to PQ and PR problems. (UPS systems consist of backup generators, power converters, and energy storage units, such as batteries, control units, switches and relays). For example, in the telephone industry, availability exceeds $99.999 \%$ in the United States. To achieve this level of reliability in the face of utility power disruptions requires large banks of lead-acid batteries. These are automatically switched by UPS systems to provide backup power when the utility-supplied power goes down. Increasingly, flywheels are being used in place of lead-acid batteries as energy storage devices for the UPS application. Power quality devices for smaller applications include relatively simple, low-cost devices aimed at specific problems, such as power sag or under voltage, power surge or over voltage suppression, brownouts, spikes, impulses, voltage transients, line noise, power factor correction, and frequency variation.

Figure 2 summarizes the major forms of power quality disturbance (the typical voltage waveforms are shown in the figure) along with currently available methods to mitigate the disturbances (or "condition" the power) (Hawaiian Electric Company, 2001). Note that power reliability is included in this table within the overall "power quality" category. Figure 2 is included to show the number and variety of existing, commercially available power quality solutions.

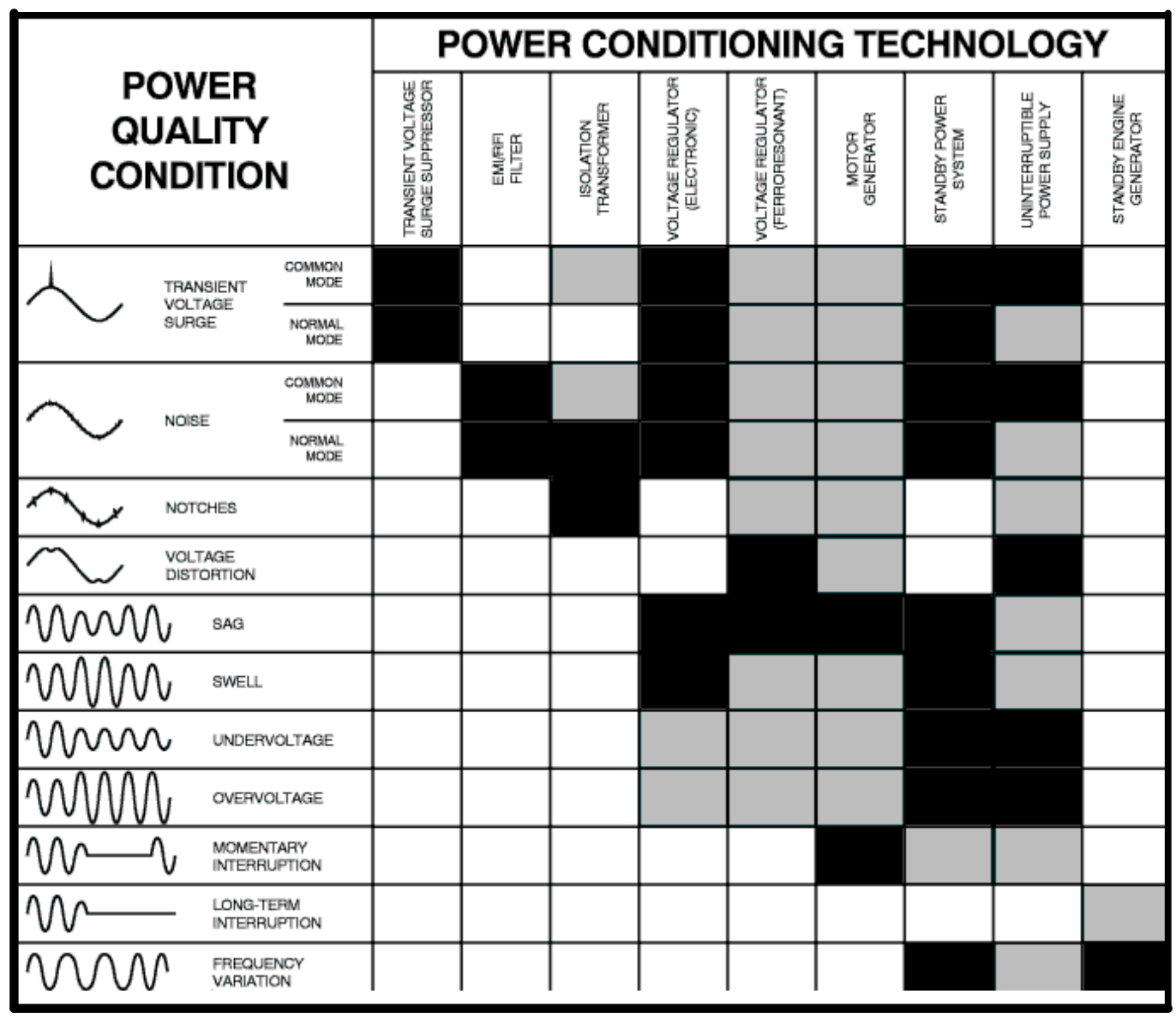

LEGEND

Gray Power conditioning technology likely to correct the PQ condition.

Black Power conditioning technology may not fully correct the PQ condition.

White Power conditioning technology not applicable.

Figure 2. Power Quality and Reliability Disturbance Versus Available Mitigating Technologies 
These measures and combinations of measures worked well as late as the middle 1990s, providing adequate power quality and reliability and financial protection for most customers. However, fundamental changes in the manufacturing and service industries, enabled by electronics and computers, continue unabated. Therefore, the value of the goods, processes, and services affected by PQ and PR continues to increase. While the UPS and insurance solution works in many situations, it has not yet become universally acceptable. UPS has problems of its own, including battery life, weight, and hydrogen gas emissions; power factor impacts; harmonic currents on input and output lines; and overall cost.

The net result of growing electricity supply and quality problems is increasing financial impact on business, industry, institutions and governments in the United States. There is a risk that, in some cases, the economic losses resulting from unacceptable PQ and PR may reach levels that are not insurable. Finally, it is important to note that the financial losses accrue not only to those directly affected by power interruptions, but also to their suppliers, customers, financers, and insurers.

Both new technologies and changes in utility system organization and operations may provide a number of better solutions. The concurrent trend towards a utility infrastructure containing distributed energy resources, energy storage systems, and central control may offer future relief from grid-transmitted and facility-caused disturbances. The financial impacts of less than adequate power quality and reliability and the consequent demand for solutions, coupled with the unique characteristics of DER, offer an opportunity for more rapid deployment of DER as primary and backup power supplies. DER has the potential to overcome utility and site-specific supply problems, and to help compensate for the limitations of the existing distribution grid.

\subsection{Definition of Power Quality and Power Reliability}

Power quality and power reliability are related but separate aspects of the electric power supply. While some experts and publications treat both PQ and PR as subsets of "power quality," we treat each as a separate major category, or "condition," of the power supply. As noted, the lack of, or diminishment of, both power quality and reliability has measurable economic impacts for the power user (the customer). The consequences of poor PQ and PR can range in magnitude and probable cost from inconvenience as a result of equipment failure to damage and lost productivity.

Power quality has to do mainly with the supply of voltage to meet the needs of the customer and is measured in terms of voltage stability, frequency stability and the "purity" of the waveform. High power quality implies the near absence of measurable voltage sags and very short interruptions, voltage surges, voltage spikes, waveform harmonics, and so on. (The specific features of power quality are discussed in Section 3.0). PQ related problems occur whenever conventional AC electric power deviates momentarily or continuously from established standards for voltage, frequency, and waveform. (Although a complete interruption of supply could be included in this category, we consider it part of the PR category).

Transient voltage spikes, for example, can and do destroy data and solid-state components. Voltage sags can stress solid-state electronic components. Diminished power quality also impacts even the ubiquitous, and otherwise robust, induction motor in service in millions of consumer appliances and commercial and industrial machines. For example, sustained low voltage (a power quality event) can damage the motor that drives the home refrigerator compressor because of the increased current that must be delivered to meet its power demand.

Power reliability means availability of power. Simply stated, the power is there or it is not. In practice, reliability is measured in terms of the frequency and duration of both complete interruptions of supply or partial interruptions of supply (that is, ability to meet only a portion of the power demanded by the customer). PR problems occur as a result of unplanned interruptions in the supply of power. Interruptions can vary in time, in the industrialized nations, from a fraction of an electrical cycle (a few 
milliseconds) to many hours in duration. Momentary and longer power interruptions can cause unprotected solid-state systems to "crash," unless sustaining power equipment intervenes.

\subsection{Relevant Standards}

A number of standards that address requirements for the quality of the electric power supply must be carefully analyzed to evaluate their impact on the power quality benefits that might be achieved by DER. The main relevant North American recommended practice for electric power supply voltage and end user current distortions is IEEE-519-1992 (IEEE, 1992). It sets recommended limits of 5\% total harmonic distortion [THD] with no individual harmonic exceeding $3 \%$ of the fundamental. In addition, the Computer and Business Equipment Manufacturers Association [CBEMA] has a recommended guideline, Federal Information Processing Standards Publication 94, on the voltage sags and surges that should be tolerable by office and business equipment. However, many appliances and devices in use are more sensitive than specified by the CBEMA curves. The utility industry has also established a recommended profile of allowable voltage tolerances for power delivered to the customer, as specified in American National Standards Institute [ANSI] Standard C 84.1-1995 (ANSI, 1995). (This standard is discussed further in Section 4.1). Currently, the Distributed Resources and Electric Power Systems Interconnection Working Group under the IEEE Standards Coordinating Committee 21 (SCC21) is finalizing Standard P1547, Standard for Interconnecting Distributed Resources with Electric Power Systems. The basis of the rules imposed by this draft standard is to allow the safe and reliable integration of DER into radial distribution systems with the lowest possible cost.

\subsection{DER Technologies, Characteristics and Operating Configurations}

A unified and generally accepted definition of DER does not exist. We define DER to include all power generators and energy storage systems outside of the realm of medium- and large-scale conventional power plants (such as coalfired steam turbine generators and hydroelectric generators) that are rated at hundreds of megawatts up to thousands of megawatts. The fundamental and distinguishing feature of DER power systems is that they can be largely or completely factory manufactured, assembled, and tested; and easily shipped, installed, and commissioned as complete modules. Hence, they can go into service very quickly, where and when needed (lead times are very short compared to those required to bring a large-scale power plant on line).

Willis and Scott (2000) provide a good working definition of DER (or DG). (While they limit DER to generation sources, we include energy storage systems within the definition, as stated above).

"Distributed generation, or DG, includes the application of small generators, typically ranging in capacity from 15 to $10,000 \mathrm{~kW}$, scattered throughout a power system, to provide the electric power needed by electrical consumers. As ordinarily applied, the term distributed generation includes all use of small electric power generators, whether located on the utility system, at the site of a utility customer, or at an isolated site not connected to the power grid.

By contrast, dispersed generation, a subset of distributed generation, refers to generation that is located at customer facilities or off the utility system. Usually, dispersed generation is also understood to include only very small generation units, of the size needed to serve individual households or small businesses, in the capacity range of 10 to $250 \mathrm{~kW}$.

Most types of distributed generators utilize traditional power generation paradigms ? diesel, combustion turbine, combined cycle turbine, low-head hydro, or other rotating machinery. But in addition, DG includes fuel cells and renewable power generation methods such as wind, solar, or low-head hydro generation. These renewable generators are often lumped into the " DG" 
category because their small size makes them very convenient to connect to the lower voltage (distribution) parts of the electric utility grid."

\subsection{Overview of DER Technologies and Deployment}

It must be emphasized that DER systems, by definition, are distributed throughout the lower voltage power distribution part of the T\&D network, close to the loads (end-use devices) they serve. Thus, the power produced by DER systems does not generally travel over the high voltage transmission system. Although this power could find its way back to the high voltage transmission system under some conditions, it is believed that the main impacts of DER on the T\&D system will be confined to the distribution network portion. This generalization may change in the future, however, if the total DG grows to equal or exceed the total amount of centralized generation. A longer-term problem with too many distributed resources could also be the redistribution or effective reduction of generator inertia below levels that are needed to protect the overall stability of the grid.

Grid-connected and off-grid configurations of DER are often referred to as grid-interactive and gridindependent operation, respectively. Grid-interactive DER refers to configurations of DER that can operate in parallel with the grid and reliably connect and disconnect as required. Grid-independent DER refer to configurations where DER have no connection with the utility network. In these configurations, the existence of DER is "invisible" to the grid.

Power generation technologies, in general, were developed to provide electricity as a commodity (that is, "quantity" of power). It is only recently that their potential power quality/reliability benefits as distributed resources are beginning to become major drivers for the refinement of established generating technologies and for the commercialization of new technologies. Thus, there are, in principle, many DER technologies. These include generation systems, such as microturbines, fuel cells, diesel generators, and solar and wind arrays; and advanced storage systems, such as flywheels, advanced battery systems, super capacitors, and super conducting magnetic energy storage [SMES]. There are also hybrid combinations of these systems, such as packaged diesel/wind generators with battery backup.

Many of these DER technologies are still in their infancy, seeking market validation to reduce cost and gain commercial acceptance. Commercially available DER and DER systems under development include both older conventional technologies, such as diesel and gas-powered generator sets and gas turbine generators, and rapidly emerging technologies, such as fuel cell power generators and SMES. Many of the emerging DER technologies are already being demonstrated in near-commercial configurations throughout the world.

Fuel cell systems have been highly publicized as one of the few DER technologies capable of mass deployment (i.e., down to the residential level). Because fuel cells highlight several issues with respect to the use of emerging power generation technologies for DER systems, a brief discussion is presented here.

Fuel cell systems typically consist of a fuel reformer (which isolates and produces the hydrogen needed by the fuel cell from the main energy source ? natural gas, gasoline, propane, etc.) and a series of fuel cell membranes that are arranged in "stacks" to produce the desired voltage from the system. Like batteries, fuel cell systems produce electricity in direct current [DC] form, which must ultimately be "inverted" to alternating current for use in most commercial and industrial applications (see Appendix A). Fuel cell systems can be arranged in series, feeding multiple DC inputs to a single inverter that converts the DC to AC. Alternatively, fuel cells can be connected in parallel to supply the output of individual cells to a series of inverters that, in turn, are controlled to provide a synchronized AC output.

Unlike batteries, which produce instantaneous DC on demand, fuel cell systems have a relatively slow response time to step changes in the load and naturally deliver varying voltage DC. As a result, fuel cells 
are typically operated in conjunction with batteries as a combination power source capable of meeting instantaneous load changes. The battery, or series of batteries (commonly referred to as a "DC bus"), serves as a "sink" for the power inputs. One or more inverters are then used to "invert" the direct current from the battery to AC required by the load. One or more battery charge controllers control the relationship between the fuel cell stacks and the battery. These controllers respond to instantaneous changes in the load by ramping up the fuel cell to provide the additional voltage necessary to replace the voltage drawn from the battery. As a result, the overall system is dominated by the operating characteristics of the batteries and battery charge controllers, and the fuel cell outputs must be arranged to match the input requirements of the battery charge controller.

The anticipated and, to some extent, already demonstrated benefits of DER in the utility grid power system have been extensively publicized. One listing of these benefits is shown below. The last benefit pertains directly to work in this project.

- DER deployment allows critical industry to stay at its current location, even if the local grid is or becomes unstable and unreliable.

- DER deployment obviates the need for large T\&D investments.

- Some DER generation technologies and all storage technologies allow deployment with minimal or no air quality permitting.

- High-efficiency fuel cells and microturbines, for example, reduce the operating fuel cost and free up natural gas for use at other locations.

- Use of zero- or low-emission technologies, such as fuel cells, permit the continued use of other higher emitting generating plants. This increases the overall power available.

- DER technologies have the ability to put the highest quality power into the grid, thus increasing grid reliability and stability.

Given this list of benefits, coupled with the limited new investment in large-scale power plants and T\&D infrastructure, it is not surprising that there is a clear trend to large-scale deployment of DER in the gridinteractive mode. This deployment is expected to be over a broad spectrum of unit sizes, ranging from less than $1 \mathrm{~kW}$ (for example, roof-top mounted solar photovoltaic systems, a rapidly growing area of DER) to many thousands of kilowatts (e.g., readily available dieselgenerator sets).

Some DER units already operate in the grid-connected mode throughout the United States. However, the penetration of DER into the transmission and distribution networks is still relatively small. Furthermore, most DER units are purchased today primarily as backup power sources for commercial and industrial facilities, where they operate only when called upon and then only in the grid-independent mode (that is, completely isolated from the grid, supplying power only to the customer's load). Some owners and operators of these units have taken advantage of the opportunity from time to time to provide distribution feeder "peak shaving" support to local utilities in the grid-connected mode of operation. Of course, peak shaving at the distribution level occurs whether DER is grid-connected or not.

It is clear that more of these backup power units will be operated in this mode. Nevertheless, as long as penetration of DER on the local distribution network is low and grid-connection is infrequent, DER units can often be operated with little or no concern for the impact (positive or negative) on the power quality and reliability of the larger transmission and distribution system. That is, the continuous power needs 
and/or power quality needs of the DER owner will be met and local peak shaving benefits will be achieved. However, the benefits of the specific DER installation to the overall T\&D system are usually very small and often not taken into account. As utilities move to exercise control over the scheduling of the grid connection and power output of DER units (that is, centralized DER dispatch) to meet the needs of the distribution system, and as more DER units are deployed, the potential for both positive and negative impacts is expected to increase greatly.

\subsection{Energy Technology Development and Markets for DER, Power Quality and Reliability}

The energy technology industry today is driven by four main market factors. These factors are also responsible for the investment in and the rapid emergence of distributed energy resource systems and the basic underlying technologies.

- The absolute need for more power to serve existing users connected to the grid and the estimated two to three billion people in the world (mostly in the so-called developing countries) that have no access to electric power in the quantity or of the quality enjoyed by the rest of the world.

- Demand for high quality power, accelerated by the growth of the "digital" economy. The emergence of the "digital" economy is not confined to the developed world, where power is supplied via integrated power transmission grids. For example, the high volume manufacture of solar photovoltaic cells can be carried out anywhere in the world. However, very high power quality and reliability of supply, whether from the existing grid or from new generation sources, are paramount, regardless of location.

- Deregulation of the energy merchant industry, primarily in North America and Europe, has resulted in a segmentation of electric power products and prices, including power quality and reliability.

- Advances in technology and manufacturing processes have made new energy generation, storage and energy management technologies, including those that underpin DER, economical. New sources, such as fuel cells, for example, could dramatically accelerate the trend to distributed generation because these sources are small (and therefore can be factory mass produced), easily sited, environmentally benign (quiet and clean) and operated using a variety of fuels. Reciprocating internal combustion engine generator sets (gasoline and diesel engines) and, increasingly, micro gas turbines, already serve DER markets. Also, solar photovoltaic [PV] arrays, when combined with larger scale energy storage (on the order of 1 hour and more), are already a viable DER backup power system in some cases.

Within the overall market for electric power, the power quality and reliability market segment is today driven primarily by the technology, telecom and Internet-related industries that demand guaranteed power reliability and quality. (Essentially, more transistors per chip means lower chip voltage; lower voltages are more sensitive to voltage fluctuations). Also, installations such as data centers require very large amounts of power at extremely high levels of quality and reliability.

Current commercial solutions to the demands of these industries include UPS that incorporate batteries, flywheels and even SMES units that enable continuous high-quality power to be delivered to the end use, regardless of the status of the grid-supplied power. Typical UPS system storage capability is on the order of a second up to several minutes ? enough time to ride through a short-term power disturbance/ interruption and, if necessary, to bring backup DER units on line to supply the load. Distributed energy resources, particularly engine generator and diesel generator sets, are already integrated with these UPS systems to provide continuous power whenever the main power supply is disabled for extended periods. 
As a result, distributed energy resources, working with UPS, remove the need for the customer to place primary reliance on the grid to obtain acceptable PQ.

\subsubsection{Markets}

There are many markets for DER systems, each with its specific applications, technical requirements, economic equation, distribution needs, and end users. Furthermore, both product development and market evolution are moving quickly. Given this environment, it is difficult to characterize where the markets and technologies are headed. Nonetheless, it appears that, at present, two overall DER markets are developing:

1. Commercial/industrial. This market exhibits a faster adoption rate for DER because segments of the market are very sensitive to the economic advantages of DER deployment. Also, typically, this market requires DER units with higher power ratings and concomitant higher margins for the vendor.

2. Residential. This market is seen by many to be a vast opportunity. However, performance and cost requirements are stringent. Distribution of the product is a major challenge. The market has not been penetrated yet. Very high volume manufacturing, extensive distribution networks and much lower sales margins would be demanded in this market.

\subsubsection{Market Applications}

DER market applications appear to fall into five main categories. In all cases, reliability and quality of power delivered are overall requirements.

- Grid replacement primary generation. For this application, performance requirements are stringent and low cost is paramount. In this application, the customer effectively becomes a self-generator, completely disconnected from the grid supply.

- Grid parallel primary generation. Here, the DER unit operates as a supplier of power to the grid. Clearly, the DER cost to generate must be competitive with other power sources supplying power to the grid. The DER unit could provide voltage support and, thereby, an additional power quality value to the grid operator. To date, DER in this category are typically operated only as electric current sources; that is, the only benefit of the DER units is the power delivered.

- Remote power. In this application the premium is on reliability, because there is no grid to backup the DER. Constraints on the cost to generate the power vary widely, depending completely on the specifics of the installation.

- Peak shaving. Here the highest value is placed on low capital cost and siting flexibility, while efficiency requirements are moderate. Typically, the grid operator owns and operates DER during peak demand periods to limit the demand on a feeder or group of feeders. The ability to site DER units, or to find and operate an existing DER unit at the optimum location, is critical. Also, the grid operator must have unrestrained access to operate the DER as required. While DER could also provide power to the grid at other times, its prime value is peak shaving. Operation of the DER as a backup unit for loads near its location is, of course, possible because, by definition, if the grid power fails, there is no need for peaking supply.

- Backup power. Here the application of DER is as backup power for the customer in the event of failure or curtailment of the grid supply. Here, the customer places the highest value on reliable operation, while efficiency is much less important. 


\subsubsection{Power Quality Markets for DER}

Three power quality markets where DER has an existing or emerging role are:

1. Backup power. This is already a large and well-established market for DER devices, primarily in commercial settings that are greatly impacted by short and/or long duration power quality events and power disruptions. In this application, reliable operation and siting flexibility are generally more important than efficiency.

Engine generator sets (driven by reciprocating internal combustion engines) currently dominate this market, the result of more than 100 years of continuous development and a vast worldwide manufacturing, distribution and support infrastructure. DER devices such as microturbines and fuel cells are expected to displace some engine generator units in this market, as they become cost competitive. The worldwide market for backup power is already valued at more than $\$ 5$ billion.

2. Power quality - primary generation. Here, very high quality power is required for sensitive industrial and commercial loads. Operating in parallel with the grid in various configurations, DER units act as the primary power supply. The grid and the DER work together to ensure very high reliability and quality. As discussed elsewhere in this report, digital economy applications are expected to spur most of the growth in this market. However, other traditional applications already require continuous power, including many materials processing plants. In this market, systems can be configured with the DER supplying the load continuously and with the grid as the backup power source. Clearly the DER unit must be inherently reliable, well operated, and well maintained. The transfer from the DER source to the grid (whenever necessary) is carried out seamlessly through complex and sometimes costly transfer switch systems. In some applications, the systems might be more correctly termed UPS because energy storage and the necessary switchgear and control are included to ensure truly seamless transfer. Many other configurations are possible.

3. Power quality - residential applications. The demand for higher quality power in the home is expected to grow. The prevalent consensus is that this market will ultimately be served by very flexible DER systems operating mostly in the off-grid mode, but with the ability to automatically synchronize to the grid and to deliver excess power to the grid, or to accept power from the grid to augment the DER output during peak home demand periods. The supervisory control unit would receive both electricity price and load demand signals, dispatching the DER in the highest value operating mode consistent with the home demand, grid demand and energy price information.

\subsection{Purpose of the Project}

Work in this project addresses the ability of DER technologies to enhance the quality of the power delivered to the customer and to improve the reliability of the overall power supply system. Because electricity generation, $T \& D$, and load systems are very complex, it is not obvious that combinations of existing, under development, and proposed DER systems, grid integration methods, and DER control methods will capture the maximum number of reliability and power quality benefits. Therefore, more and better information, evaluation, and assessment are needed to answer three vital sets of questions:

1. How suitable are these technologies now and expected to be in the future for stabilizing the utility network (that is, maximizing the reliability and quality of power)? Related directly to this is the question, which power quality and reliability characteristics have the highest economic value (or payoff), how are these characteristics measured and what is the relationship between the measured value of the characteristics and their economic value? When are points of diminishing return reached? 
2. How should DER systems and networks of DER units be designed and operated to achieve the desired power quality and reliability improvements? Is centralized control feasible and desirable and, if so, under what conditions?

3. What is the best method or methods to assess the value of the various DER technologies as power quality and reliability enhancing tools?

The overall objective of this project is to provide answers to these questions. In so doing, we will characterize, assess, and evaluate the ability of existing, under development, and proposed DER technologies and essential related systems to enhance (or detract from) the supply of high quality and reliable power from the utility network of the future. Key project deliverables are characterization of technologies from the perspective of power quality and reliability performance, along with a set of specific recommendations for $\mathrm{R} \& \mathrm{D}$ needed to meet the future power quality and reliability requirements for important classes of end users and grid integration scenarios.

We recognize that there is a growing demand for less vulnerable end-use electrical equipment and that end-use based solutions exist and are being implemented. Therefore, we will closely monitor and assess this trend and evaluate its impact on the implementation of DER in the grid.

Willis and Scott (2000) assert the following with respect to the value and limitations of DER in the utility grid:

"A properly designed electric utility system, operating effectively, provides very high levels of service availability, typically on the order of $99.96 \%$ or better. Frankly, that level of reliability is difficult to improve upon with any type of on-site generation, unless very high quality equipment is used, with full and often multiple levels of redundancy.... A high quality DG unit has a service availability of about $95 \%$ (including time out of service for both scheduled maintenance and unexpected failures and repairs). The best have availabilities of about $98 \%$. Thus, it takes redundancy, sometimes up to $100 \%$ additional capacity, to assure that DG power will 'always be there'. In a majority of cases, DG cannot both lower cost and provide higher reliability of service than that provided by the grid. In most cases, to expect that borders on fantasy.

Frequently, DG will 'win' the selection as preferred power supply to a particular site, because it can be tailored to have lower cost than the power grid when cost is most important, or to provide higher reliability when that is crucial. Distributed generation is tailorable in both cost and reliability, to a degree that the electric utility often cannot match.

DG offers great value because it provides a flexible way to choose a wide range of combinations of cost and reliability.

As a result, DG most often 'wins' a match-up with the electric utility system when the particular need falls toward either end of the cost-reliability spectrum .... DG installed at a site, without backup, can often provide a lower cost for power than the local grid, but with more expected hours of service interruption each year. Some electric consumers don't care. Reliability is not so important to them that they are willing to spend any more than necessary: cost is all-important. In these cases, DG 'wins'.

At the other end of the cost-reliability spectrum, many commercial and industrial power users find unacceptable $99.97 \%$ availability ( 2 hours without power a year, about the average performance of most electric systems). Here, redundant DG can be installed, with the right type of 'rollover switching'. Now the consumer must pay more, but has much higher reliability than 
the grid. Without a doubt, the electric grid could be reinforced to equal these levels of reliability, using redundant circuits, automatic rollover and even static switches, but usually the cost to get high reliability (only a few minutes a year of expected outage) are much higher than for DG. In these situations, DG wins again."

One of the main objectives of our work is to test the validity of Willis and Scott's assertion that "DG offers great value because it provides a flexible way to choose a wide range of combinations of cost and reliability." In addition, Willis and Scott point to the main challenge for DER systems. That is, to deliver equivalent or better availability than the T\&D system at the same or lower cost. Thus, a further key objective of this work is to determine whether DER technologies and systems can be developed and matured to meet that challenge at a meaningful level of market penetration. 


\subsection{The Conventional P ower T ransmission and D istribution System}

The interconnected North American electric power T\&D system (or "grid") has been called the largest machine ever created by man, because an interconnected power system depends on all of its components operating together and in coordination with each other. All generators synchronized with the grid are physically tied together through a complex web of transmission lines and hierarchical control systems.

\subsection{Function}

The function of the conventional power system is to produce power at central generating stations and deliver it to the customers at their place of consumption in a form that customers can use. Hence, the primary requirement of the T\&D system is to "cover ground" - that is, to reach every customer. Four main requirements (in response to customer needs) define today's T\&D system in the United States (Willis and Scott, 2000). If DER is to become an alternative, it must also meet these overall requirements:

1. The system must provide an electrical path to each customer. It must cover the service territory.

2. The system must satisfy each customer's peak demand for power. Stated differently, the system is expected to deliver the quantity of power demanded by each customer at all times.

3. The system must provide highly reliable service (it must be "robust"). The availability of power delivered by the T\&D network in much of the United States is now expected to exceed $99.97 \%$. Willis and Scott (2000) noted, “...utilities have gradually adjusted to designing their system to a higher level of expected service reliability. In the late 1990s, something on the order of 2 hours a year of interruption was the guiding concept about 'what is correct' for most utilities, as opposed to 4 to 8 hours, which was typical 3 to 4 decades ago."

4. The T\&D system is expected to supply the quality of power required by the customer. This has to do mainly with the supply of voltage to meet the needs of the customer and is measured in terms of voltage stability and the "purity" of the current. High power quality implies a near absence of measurable voltage sags and very short interruptions, voltage surges, voltage spikes, waveform harmonics, and so on. It is important to understand that customer requirements for power quality are not uniform.

\subsection{Structure of the Transmission and Distribution System}

Figure 3 is a schematic representation of the conventional T\&D system with centralized generation. It shows the basic hierarchical structure, starting with the generating station (or "power plant") and ending at the customer's service entry point (e.g., the distribution panel in a home). The most significant feature of the T\&D system is that it is configured to connect the generating stations to the loads through nodes called substations.

Power flows through a number of voltage levels as it moves from the generating stations to the customers. Central generating stations are generally connected by step-up transformers to transmission lines (having the highest power carrying capacity). At the switching substations other transformers step down the voltage and the power is fed to a number of sub-transmission lines that supply distribution substations. Sub-transmission refers to a lower level in the grid hierarchy that typically interfaces the long-distance bulk transmission backbone with the distribution network supplying end-use customers. Usually, the T\&D system at the transmission and sub-transmission levels is "networked" as a grid so that at least two 
sub-transmission routes supply each substation. This ensures that power delivery can be maintained should one sub-transmission route fail.

Typical transmission voltages in the United States include the extra-high voltage of $765 \mathrm{kV}$, and the 500 $\mathrm{kV}, 345 \mathrm{kV}$ and $230 \mathrm{kV}$ voltages of the most common long-distance transmission lines. In relatively few instances, bulk power is also transmitted as high-voltage DC. This requires AC to DC and the reverse DC to AC conversions, respectively, at line terminals so that the DC power can be received from and delivered to the AC grid. Other common transmission voltages include $161 \mathrm{kV}, 138 \mathrm{kV}, 115 \mathrm{kV}$ and 69 $\mathrm{kV}$. Of these, the lower voltages, $115 \mathrm{kV}$ and $69 \mathrm{kV}$, are sometimes called sub-transmission voltages.

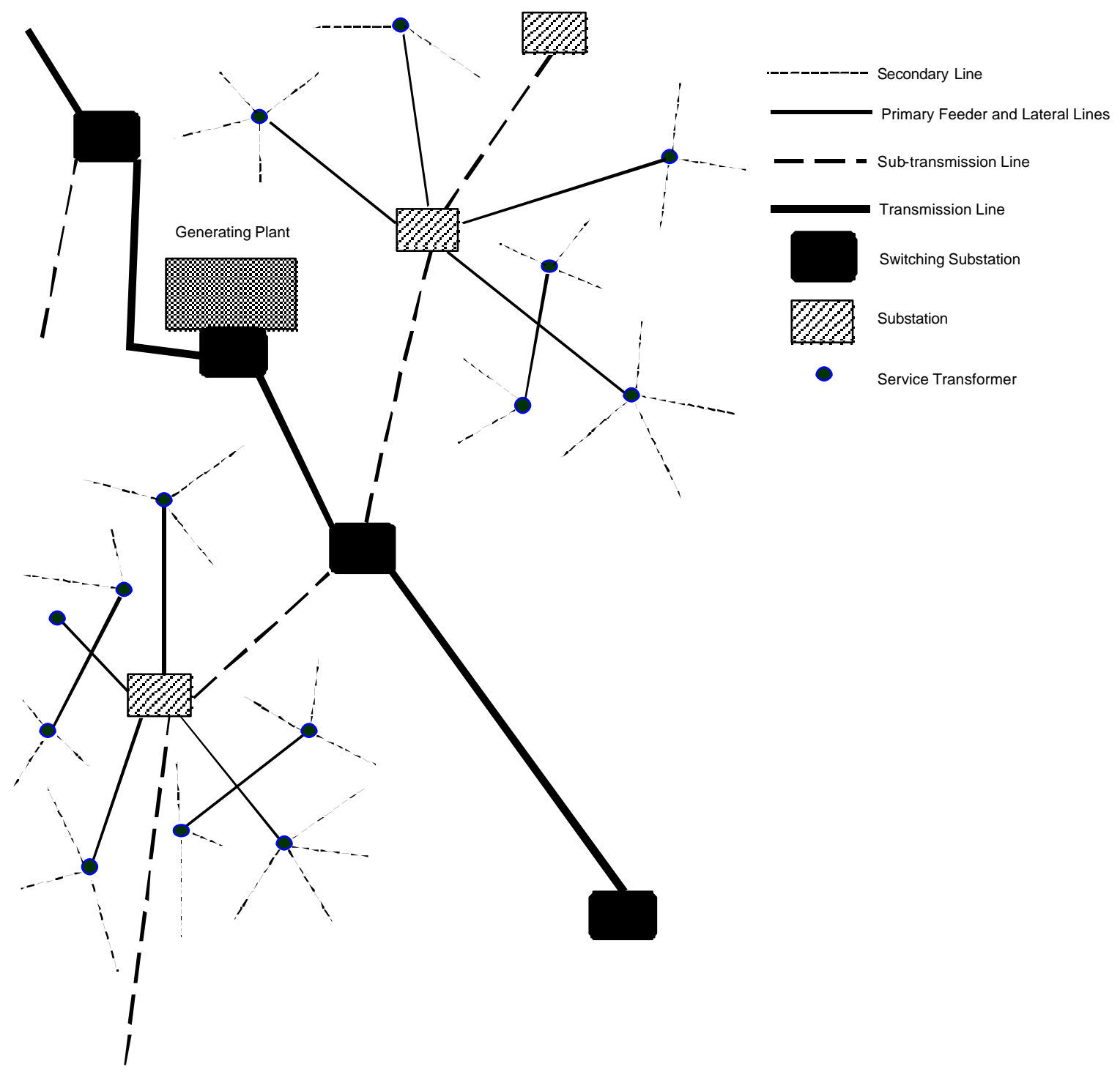

Figure 3. Schematic of the Conventional Grid System

Each substation transformer is a node of the distribution portion of the system. While substations are actually an assembly of transformers, switches, circuit breakers and other ancillary equipment, such as 
voltage control capacitor banks, reactors, metering and control equipment; voltage-changing transformers are their key elements. Substation layout and complexity vary widely depending on the application.

The distribution system is the infrastructure that delivers power from substations to consumer loads. Typically, but not always, radial in nature, the distribution system includes feeders and laterals. Typical voltages are $34.5 \mathrm{kV}, 14.4 \mathrm{kV}, 13.8 \mathrm{kV}, 13.2 \mathrm{kV}, 12.5 \mathrm{kV}, 12 \mathrm{kV}$, and sometimes lower voltages. A specific service territory is typically supplied at only one or two of these distribution voltages to minimize the inventory costs of spare parts and equipment.

Radial feeder lines (at a lower voltage than the sub-transmission level, as noted above) fan out from each substation, in turn supplying power to the lateral lines that feed the service transformers. Except in very high population density areas, there is generally little redundant network structure at the feeder level because of the prohibitive cost (i.e., there is seldom a redundant supply path to most end-use loads).

The service transformers reduce the voltage to the final customer supply level, and the lines from the service transformers connect directly to the various customers' facilities, completing the power flow path from generating plant to the customer. In effect, therefore, a feeder can be thought of as a local T\&D system.

The electric power grid typically operates as a three-phase network down to the level of the service transformer. Thus, feeders generally carry three-phase power. As one gets closer to the loads (many of which are single phase), single -phase laterals provide spurs to the various customer connections. The service transformers supplying single-phase loads are connected in a manner that is designed to balance the total load on each phase of the three-phase distribution system.

\subsection{Network Operation Considerations}

Three-phase electricity is electricity transmitted along three parallel conductors with the three voltage waveforms $120^{\circ}$ out of phase with each other. Under ideal (balanced) conditions, each conductor carries one-third of the total load. This system provides advantageous characteristics with respect to operating rotating machines (both generators and motors) by inducing a smooth rotating magnetic field that applies a consistent torque to the rotor. It also offers significant advantages for electric power T\&D because each of the three phases cancels each other out when combined vectorially. This makes it possible to string only three voltage-carrying conductors, relying on the mathematical cancellation of this power to provide a virtual neutral. Eliminating the return wire permits significant cost savings. Thus, nearly all T\&D power lines have only three conductors. The grounding of neutral points on the three-phase windings of electric equipment allows the earth to provide the fourth conductor. This typically conducts some of the circuit current if the distribution of electrical loads becomes unbalanced between phases, or as a result of system faults and other malfunctions.

Service voltage to the customer can be as low as $120 \mathrm{~V}$ single phase or 120/240 V single phase (in the latter case the $240 \mathrm{~V}$ secondary of the service transformer has a center tap that also provides two $120-\mathrm{V}$ single-phase circuits). Customers with larger loads typically use three-phase power, with 120/208 V or $277 / 480 \mathrm{~V}$ service $^{1}$. Some very large industrial customers may require higher voltage service. In these cases, the customer is often responsible for providing the transformers and other infrastructure to serve all of the lower voltage requirements needed at its site.

A typical service transformer (either ground mounted or pole mounted), supplying 2 to 10 residences, converts the three-phase power at a distribution voltage of $13.8 \mathrm{kV}$ (transformer primary), for example, to power at $120 / 240 \mathrm{~V}$. As noted above, each secondary provides two 120-V single-phase circuits, making

\footnotetext{
${ }^{1}$ A common way to denote three-phase service is to list the line-to-neutral followed by the line-to-line voltage.
} 
it possible to supply an individual residence with both 120 - and $240-\mathrm{V}$ single-phase service. The higher voltage is required for appliances such as clothes dryers, heat pumps and electric furnaces.

System reliability tends to decrease as one moves closer to the customer. Willis and Scott (2000) state "roughly $60 \%$ of service interruptions are a result of failure (either due to aging or to damage from severe weather) of distribution equipment within $1 / 2$ mile of the customer." This points to a key advantage of DER ? it can be installed at the customer's site and, therefore, potentially mitigate the effects of the increased unreliability of the traditional T\&D system close to the customer. However, power is a function of voltage and current and, because current is bi-directional, power can flow in either direction. In existing T\&D systems, circuit breakers and other control devices may not be able to accommodate a reversal of power flow on a distribution system without replacement or modification. This is a critical consideration for the deployment of DER but is not a factor until local DER capacity exceeds the local load. 


\subsection{Power $Q$ uality Terms and D efinitions}

Perfect power quality may be defined as the continuous availability of electric power that conforms to accepted standards of voltage, frequency, and waveform. In the United States, the power distribution component of the interconnected grid supplies $60-\mathrm{Hz}$ single-phase and/or three-phase sinusoidal power to the end user at several standard regulated voltages. Depending on the character and sensitivity of end-use electrical equipment, deviations from these nominal properties of power delivered to the supply side of the meter can cause PR and PQ problems to be experienced on the customer's side of the meter. However, in general, poor PQ is considered to occur when the power supply to individual consumers deviates from the expected constant voltage and $60-\mathrm{Hz}$ sinusoidal waveform, either momentarily or for longer periods, regardless of whether the problem originates on the supply side of the meter or on the user's side. Problems are generally caused by disturbances that change the voltage, frequency and waveform of the supply.

\subsection{Power Quality Disturbances}

Figure 4 represents graphically eight major disturbance categories that cause the majority of PQrelated problems (DeWinkel and Lamoree, 1993).

(a) Outage

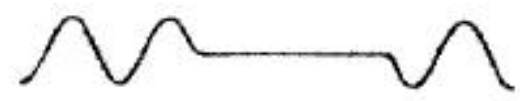

(b) Sag

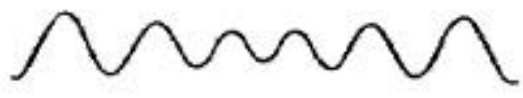

(c) Swell

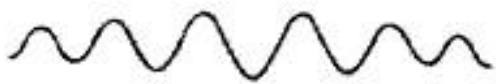

(d) Harmonic Distortion

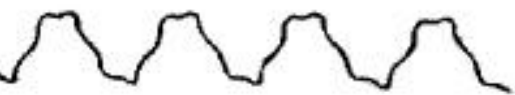

(e) Commutation Notches

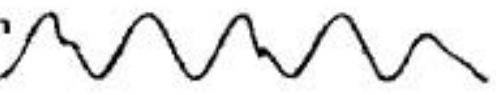

(f) Frequency Deviation

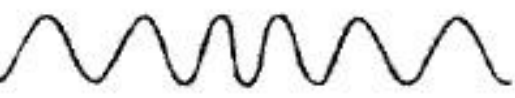

(g) Surges

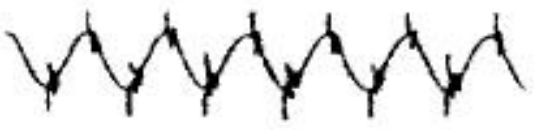

(h) Electrical Noise

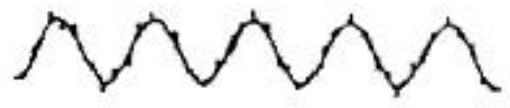

Figure 4. Principal Categories of Poor Power Quality 


\subsubsection{Outage}

The outage illustrated in Figure 4a is an absolute interruption of the 60-Hz supply (i.e., the voltage falls to zero) for one or more cycles. (It becomes a power reliability problem when it persists long enough to force all loads to cease operation.) At $60 \mathrm{~Hz}$, one cycle of the power wave lasts 1/60th of a second, or 16.67 milliseconds [ms]. A power outage of this duration is long enough to trip relays protecting a broad range of high-value electrical equipment and precisely controlled systems ranging from home computers to industrial processes. However, this type of disturbance will cause only a momentary dimming of lights and totally imperceptible changes in the operations of appliances such as water heaters, ovens and ordinary motor-driven loads. Before the age of computers and high-speed electronics, such disturbances were generally tolerable unless outages persisted for minutes to hours, or longer.

There are many causes of temporary outages, including severe weather, utility equipment failure, the automatic reclosing time needed for switching operations, the time needed to start and synchronize backup generators, and accidents involving power lines, both natural and human-caused.

\subsubsection{Voltage Sag}

The voltage sag shown in Figure $4 \mathrm{~b}$ illustrates the condition of the supply voltage temporarily dropping to some fraction of its nominal value for one or more power cycles before recovering to its standard value. A voltage sag is specifically defined as a decrease to between 0.1 per unit [pu] and $0.9 \mathrm{pu}$ in root mean square [rms] voltage at power frequency for durations from 0.5 cycles $(\sim 8 \mathrm{~ms})$ to 1 minute.

Voltage sags are usually associated with system faults but can also be caused by turning on heavy loads or starting large motors. For example, an induction motor can draw 6 to 10 times its full load current during start up. If the electric current drawn during this start up is large relative to the available fault current in the system at that point, the resulting voltage sag can be significant. While voltage sags are generally inconsequential from the typical homeowner's perspective, they can have wide-ranging impacts on sophisticated loads and many high-value industrial processes ranging from papermaking to the manufacture and qualification of computer chips.

\subsubsection{Voltage Swell}

The disturbance known as voltage swell is illustrated in Figure 4c. It is a transient of higher than standard voltage that can trip equipment protected by sensitive over-voltage relays. Persistent swells can also cause damage by over-heating unprotected equipment.

More specifically, a swell is defined as an increase to between $1.1 \mathrm{pu}$ and $1.8 \mathrm{pu}$ in rms voltage at power frequency for durations from 0.5 cycle to 1 minute. As with sags, swells are usually associated with system fault conditions, but they are not as common as voltage sags. The term momentary over voltage is commonly used as a synonym for voltage swell.

Swells are typically caused by a variety of events happening elsewhere on the supply system, including sudden load shedding and incorrect settings or functioning of distribution voltage regulation equipment. One way that a swell can occur is from the temporary voltage rise on the unfaulted phases during a single line-to-ground fault. Energizing a large capacitor bank can also cause swells.

\subsubsection{Harmonic Distortion}

Harmonics are sinusoidal voltages or currents having frequencies that are integer multiples of the frequency at which the supply system is designed to operate (termed the fundamental frequency; usually $50 \mathrm{~Hz}$ or $60 \mathrm{~Hz}$ ). Distorted waveforms can be decomposed into a sum of the fundamental and harmonic frequencies. 
Harmonic distortion originates from the nonlinear characteristics of devices and loads on the power system. For example, distortion is created in the current waveform of the DC power supply unit typically found in a personal computer, a result of the "chopping" of the input current that occurs in the AC to DC converter. This distortion is then imposed on the voltage waveform of the supply circuit as influenced by the effective source impedance of the power delivery circuit. Thus, harmonic distortion is transmitted to adjacent equipment at frequencies characteristic of power electronic devices including converters, inverters, rectifiers and switching power supplies.

Harmonic distortion levels are described by the complete harmonic spectrum, with magnitudes and phase angles of each individual harmonic component. While it is common to use a single quantity (the total harmonic distortion [THD]) as a measure of the effective value of harmonic distortion, the impact of harmonic distortion is a function of the current (or power) being transmitted. For example, THD well above the recommended maximum may not be a problem on a distribution circuit if the load demand is very low, because the magnitude of the distorted current is also very low. To characterize the impact of harmonic currents in a consistent fashion, IEEE Standard 519-1992 defines another term, the total demand distortion [TDD]. This term is the same as the THD, except that the distortion is expressed as a percent of some rated load current, rather than as a percent of the fundamental current magnitude.

If the power transmitted in harmonic components of the 60-Hz supply is large enough, wave shape distortion of the types illustrated in Figures $4 \mathrm{~d}$ and 5 can cause power quality problems with some equipment. Adverse effects of harmonics are electrical equipment malfunctions or failures as a result of over-voltage, excess heating, inadvertent switching and/or relay operation, or improper power frequency regulated functions, such as motor speed.

The effects on power supply wave shape resulting from the combination of primary and higher harmonics are shown in Figures 5a to 5d. The dashed line illustrates the distorted wave shape that results from imposition of harmonics on the fundamental frequency. Figures $5 \mathrm{a}, 5 \mathrm{~b}$ and $5 \mathrm{~d}$ show the in-phase addition of the third, fifth and second harmonic, while Figure 5c illustrates the resultant of antiphase addition of the third harmonic.

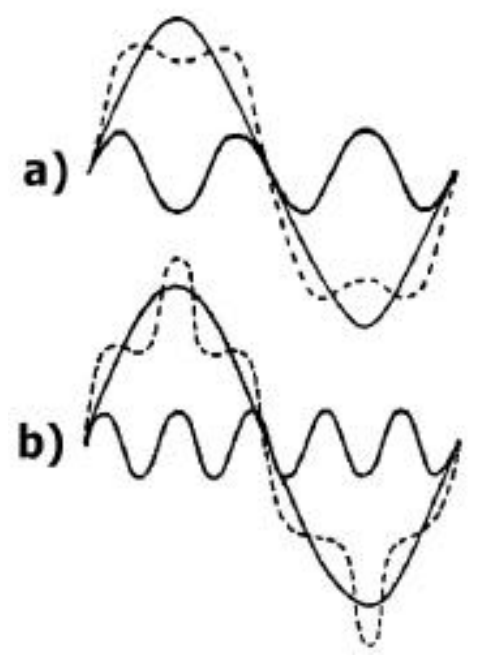

c)

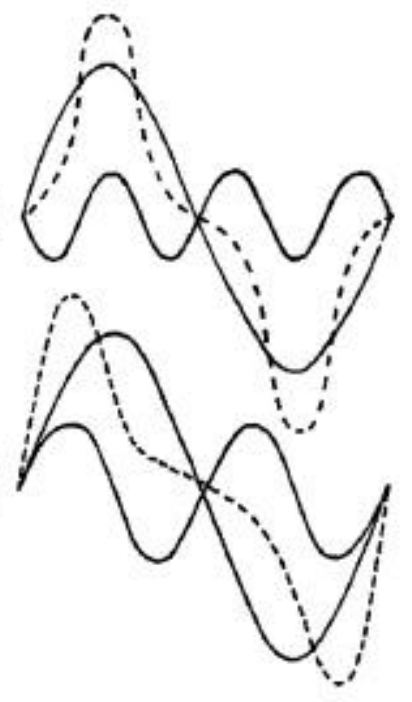

Figure 5. Distortion Resulting from Imposition of Harmonics 
We know that, although most electric power generators are designed to deliver a sinusoidal voltage waveform with acceptable harmonic content, pure sinusoidal voltage waveforms do not exist at any point in typical buildings or other distribution networks. Until the mid-1980s, there were few harmonic generating loads in buildings. Standard practice for power distribution emphasized maintaining the required power factor by use of capacitor banks. These buildings were trouble-free from the viewpoint of harmonics. Digital electronic loads arrived in force in the 1980s and introduced problems that few had imagined. The consumption caused by these nonlinear loads is far from the ideal sinusoidal waveform that power systems were designed to feed. The result has been the increased frequency of serious harmonic problems.

Adjustable speed drives [ASD], electronic ballasts, personal computers and other electronic equipment (such as in broadcast facilities) are non-linear loads that draw electric current in a non-linear fashion. For example, virtually all of today's electronic equipment uses power converters that conduct current for part of a cycle through multiple paths to convert (or "rectify") AC to DC. These converters draw current in sharp, irregular or "nonlinear" pulses compared with the smooth linear manner of an incandescent light bulb, for example. As nonlinear current flows through the electrical distribution system, it induces voltage distortion and cascading negative effects on other interconnected loads. Because of the induced harmonics, a high density of these devices can cause as many as five basic problems in the distribution network:

- Overloaded neutral conductors.

- Overheated distribution transformers and motors that may be connected to the local network.

- High neutral to ground voltage.

- Distortion of the voltage feeding these loads. Interestingly, the very devices that create the current harmonics (such as ASD and personal computers) are themselves very sensitive to the voltage distortion that results.

- Interference with programmable microprocessor controlle rs and monitoring devices.

A survey by MIRUS International Inc. (MIRUS International Inc., 1994) with respect to the current spectrum of loads in commercial, institutional and industrial settings found surprisingly simple and consistent load profiles dominated by only three harmonics ? the third, fifth and seventh. MIRUS found that there was also a trend to higher harmonic levels as a result of advances in switch-mode power supply technology.

\subsubsection{Commutation Notches}

Notching is a periodic voltage disturbance caused by the normal operation of power electronic devices when current is commutated from one phase to another. During this period, there is a momentary short circuit between two phases, pulling the voltage as close to zero as permitted by system impedances. Because notching occurs continuously, it can be characterized through the harmonic spectrum of the affected voltage. However, it is generally treated as a special case. The frequency components associated with notching can be quite high and may not be readily characterized with measurement equipment normally used for harmonic analysis. 


\subsubsection{Frequency Deviations}

Frequency deviations are defined as the deviation of the power system fundamental frequency from its specified nominal value $(60 \mathrm{~Hz}$ in North America).

The power system frequency is directly related to the rotational speed of the generators supplying the system. There are slight variations in frequency as the dynamic balance between load and generation changes. The size of the frequency shift and its duration depend on the load characteristics and the response of the generation control system to load changes. Frequency variations that go outside of accepted limits for normal steady-state operation of the power system can be caused by faults on the bulk power transmission system, a large block of load being disconnected, or a large source of generation going off-line.

On modern interconnected power systems, significant frequency variations are rare. Frequency variations of consequence are much more likely to occur for loads that are supplied by a generator isolated from the utility system. In such cases, governor response to abrupt load changes may not be adequate to regulate within the narrow bandwidth required by frequency-sensitive equipment.

Voltage notching can sometimes be mistaken for frequency deviation. The notches may come sufficiently close to zero to cause errors in instruments and control systems that rely on zero crossings to derive frequency or time.

As discussed below in more detail, system-wide frequency control is a fundamental means of ensuring that generation matches the load on the system at all times. The type of frequency deviation shown in Figure $4 \mathrm{f}$ can be transmitted throughout the grid as a result of significant disturbances. These include the sudden tripping of a large generator or a major transmission line, the occurrence of a major system fault or loss of load. Figure 6 is an example of a typical frequency variation recorded on the western system as a result of a 1200-MW generating plant tripping off line unexpectedly. In this instance, the maximum frequency swing of $0.138 \mathrm{~Hz}$ would have been transmitted throughout the grid and experienced by all loads connected to the system. Larger events, such as the 1994 Los Angeles area earthquake and the western system breakups in 1996 caused much larger transient frequency deviations. This unavoidable PQ problem could have affected the operation of equipment sensitive to frequency variations of this general magnitude.

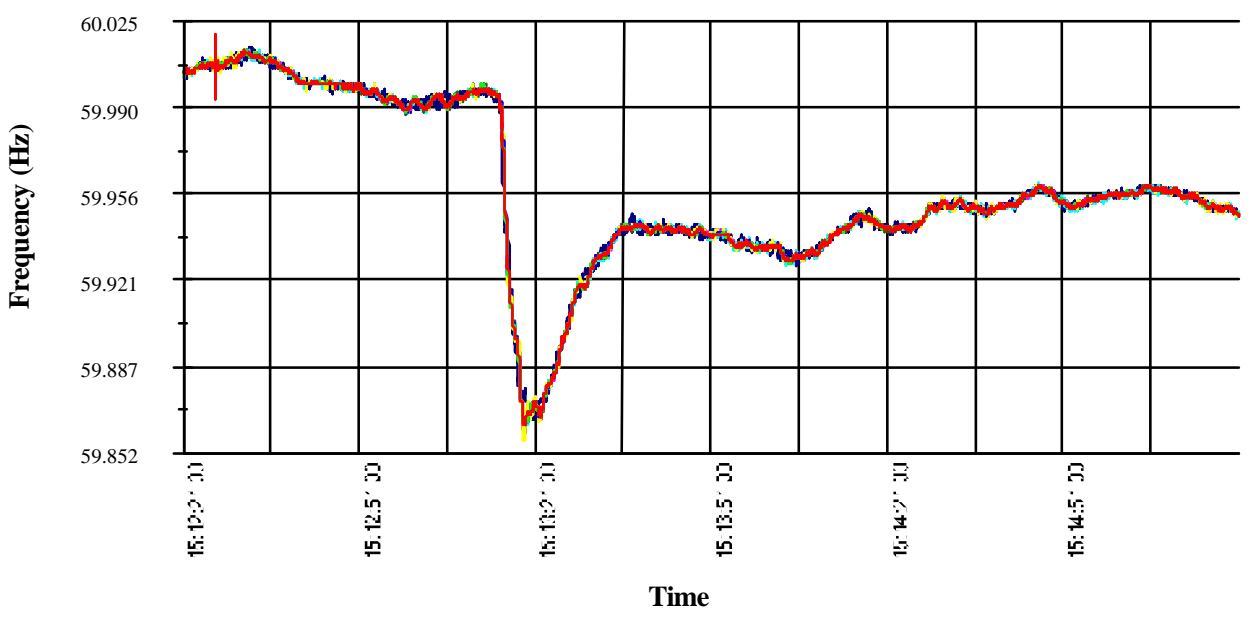

Figure 6. System-Wide Frequency Deviation Caused by 1200-MW Generation Loss 


\subsubsection{Surges}

Surges illustrated in Figure 4g are principally voltage spikes that arise from a variety of causes including lightning, power line feeder switching, capacitor switching for reactive power control, heavy motors turning off, and short circuits and faults on the system. While typically short in duration compared to a single $60-\mathrm{Hz}$ power cycle, these voltage spikes can be large compared to the nominal supply voltage and, therefore, potentially damaging to voltage-sensitive equipment.

\subsubsection{Electrical Noise}

Figure $4 \mathrm{~h}$ illustrates the final major class of disturbance experienced by end users. Electrical noise is defined as unwanted electrical signals with broadband spectral content lower than $200 \mathrm{kHz}$ superimposed upon the power system voltage or current in phase conductors, or found on neutral conductors or signal lines. Basically, noise consists of any unwanted distortion of the power signal that cannot be classified as harmonic distortion or transients.

Noise disturbs electronic devices, such as microcomputers and programmable controllers. It is generated and transmitted by numerous sources; power electronic devices, control circuits, arcing equipment, loads with solid-state rectifiers, and switching power supplies, generally in the vicinity of the affected consumer. Improper grounding that fails to conduct noise away from the power system often exacerbates noise problems.

Noise is generally less of a threat than other disturbances, but can affect sensitive equipment if not adequately filtered. The problem can be mitigated by using filters, isolation transformers and line conditioners.

\subsection{Example Of Potential Power Quality Impacts}

Figure 7 represents a hypothetical distribution of loads and mutually interactive disturbance sources on two distribution feeders served by the same substation to illustrate the potential vulnerability of any electric power consumer to PQ problems.

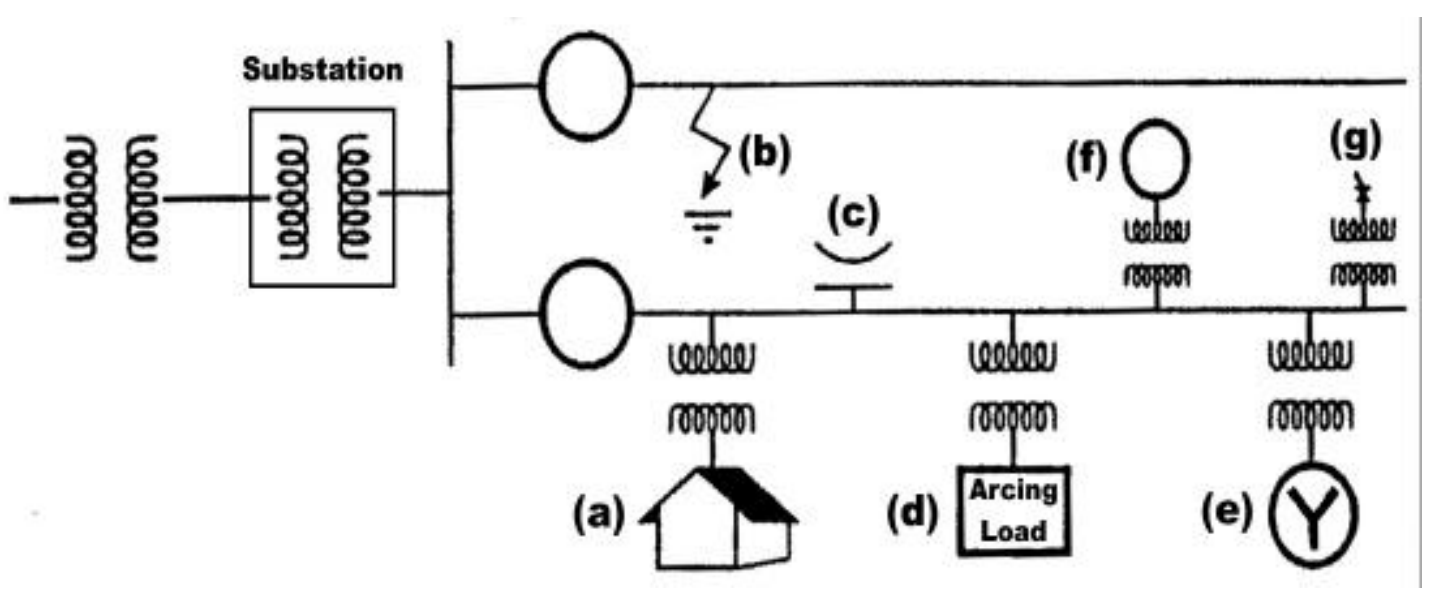

Figure 7. Loads and Disturbance Sources on Adjacent Feeders 
The key features of the identified locations in Figure 7 are as follows:

a. PQ problems are experienced in the facility representing a home, office or small industrial plant as a result of various sources of disturbance operating in the local electrical feeder network.

b. A transient fault on an adjacent feeder causes voltage sag to be communicated through the secondary bus of the common substation to all loads on either feeder.

c. Capacitors owned and operated by the utility are switched to provide voltage support and thereby impose over-voltage pulses on local loads.

d. An arcing load in an adjacent business transmits voltage flicker to nearby loads.

e. A distributed generator drops off line suddenly creating transient voltage sag throughout the adjacent feeder system.

f. A large motor starting up also causes voltage sag.

g. A large rectifier or other non-linear load causes harmonic distortion throughout the adjacent feeder system.

Regardless of the source and pathway of the disturbance, victims of poor PQ generally blame and often seek compensation from the utility that provides their electrical service. As discussed later, the utility may not always be responsible for or able to mitigate PQ problems. Before addressing this issue, consideration is given in Section 4 to the ordinary standard operation and control procedures that utilities apply to achieve the present level of power quality control. 



\subsection{U tility Control of P ower Q uality}

Conventional (i.e., acceptable by most consumers until recently) power quality control provided by utilities resides in two basic functions: voltage regulation and frequency control. These aspects of utility controlled PQ are reviewed below.

\subsection{Voltage Regulation}

The ability of utilities to maintain distribution system voltages in conformity with the standard ranges defined by ANSI is a basic aspect of PQ. Utilities regulate supply voltage to protect the power delivery system and the electrical equipment that customers use. This regulation is provided by utility-installed equipment on the distribution system. ANSI Standard C 84.1-1995 (ANSI, 1995) specifies standard voltages used in the United States. For example, the nominal $120-\mathrm{V}$ service voltage measured at the secondary terminals of a distribution transformer should be maintained within a standard $\pm 5 \%$ band (i.e., between $114 \mathrm{~V}$ and $126 \mathrm{~V}$ ) at any location along the distribution feeder.

ANSI Standard C 84.1-1995 also specifies the utilization voltage (defined as phase-to-phase or line-toneutral voltage) at the terminals of the customers' equipment. The utilization voltage is the voltage that will be supplied to end-use equipment when it is switched on. Voltage regulation provided by the utility must maintain acceptable utilization voltages to protect customers' equipment. Thus, in reference to the nominal $120-\mathrm{V}$ service, the corresponding standard utilization voltage range is, under normal service conditions, $110 \mathrm{~V}$ to $125 \mathrm{~V}$. During periods when maintenance of the utility system is in progress or the system is operating under abnormal conditions, the allowable voltage range is $106 \mathrm{~V}$ to $127 \mathrm{~V}$. Therefore, the specified allowable difference between the normal service and utilization voltage accommodates up to a 4-V drop between the secondary terminals of the distribution transformer and the electrical outlets in the customer's facility.

An enduring (as opposed to a short-term transient) deviation from the above standard voltage ranges, or even prolonged operation at the extremes of these ranges, can cause malfunction or damage to customer equipment. If the utilization voltage is persistently low, primarily resistive loads (e.g., heating, cooking, incandescent lighting) will perform at less than rated output. Heating processes will, therefore, take longer than expected. Incandescent lighting would be dimmer but, as a positive effect, would also tend to exhibit longer life. Low voltage can adversely affect motorized loads by inducing this type of equipment to draw higher than rated current and operate less efficiently. Both effects can lead to reduced productivity and shortened equipment life. In extreme circumstances, motors may fail to start or burn up rapidly while conducting stall current (an energized high current condition caused by a stalled rotor). Sustained voltages at the high end or in excess of the ANSI Standard ranges will accelerate heating processes and make incandescent lights brighter but shorter lived.

\subsection{Frequency Regulation}

While distribution voltage can vary with load and service conditions, the standard 60-Hz supply frequency, common throughout North America, is the most precisely and continuously regulated power quality component of the electricity supply.

System frequency is the means by which utilities control generation to supply the load on the system at any time. The electrical network can be thought of as a highly complex "just-in-time" delivery system in which total power generation must match total load at all times. If load increases suddenly without a corresponding increase in generation, system frequency will tend to fall, analogous to a vehicle slowing down on an ascending grade if the throttle setting remains unchanged. Conversely, the electric power 
supply will "speed up" (i.e., increase in frequency) if load on the system is suddenly removed without a corresponding decrease in generation.

System frequency control is maintained by two basic systems: one with a fast and one with a slow response. Frequency is regulated at the generator by the speed-droop characteristics of the speed governor. This is a fast responding system that speeds up a generator if a drop in system frequency is sensed. Correspondingly, generators are slowed down if a rise in frequency occurs. This process creates the equivalent of a frequency "dead band," which is too coarse to control the global system frequency at a long-term average of $60 \mathrm{~Hz}$. A complementary system, known as automatic generation control [AGC], is employed to "fine tune" global frequency across a large, interconnected grid.

AGC regulation is accomplished by dividing the grid into "control areas." In these areas, a running tally is kept of the amount of time that typically small (e.g., $0.001 \mathrm{~Hz}$ ) deviations occur in the nominal 60-Hz supply as a result of instantaneous and constantly changing differences between generation and load. This information accumulates as an "area control error" signal that is interpreted to control changes in the settings of generators specifically reserved for the frequency control function. These generators are operated both above and below a reference output setting to compensate for load changes on the system. Over periods of several minutes, the amount of time the system operates at slightly less than nominal frequency is compensated by operating for an equivalent period at slightly higher than nominal frequency. The use of AGC assures that grid frequency is maintained at a remarkably constant average of $60 \mathrm{~Hz}$ unless a major system disturbance or outage occurs. Thus, during normal grid operations, system frequency variation, per se, is unlikely to be a persistent power quality problem.

\subsection{Control Of Waveform Distortion}

As discussed previously, the ideal 60-Hz sinusoidal wave shape of grid-delivered electric power is frequently less ideal at the customer's connection. The principal cause of this is interference from other grid-served equipment operating or generating other frequencies. Also, on-line control components generate natural harmonics of the principal power waveform. However, utilities usually employ filtering and circuit configuration options that reduce the amplitude of grid-originated harmonics to acceptable and generally insignificant levels.

The harmonics that may be experienced as poor PQ on the customer's side of the meter generally emanate from equipment in the same facility or are supplied by a common distribution system. For example, the single-phase rectifier represented at location "g" in Figure 7 could generate and transmit a 120-Hz ripple voltage, the second harmonic of the fundamental power frequency. While a DER system may improve power quality, it may also be a source of harmonic distortion and voltage flicker, depending on the power converter technology and configuration used (Barker and de Mello, 2000). Control of waveform distortion from all sources is generally achieved by the design of grid-connected equipment to satisfy the requirements of IEEE Standard 519-1992. This standard specifies the maximum allowable levels of harmonic content relative to the fundamental frequency. These limits include $4 \%$ for harmonics less than the eleventh order and a maximum of 5\% THD across all frequencies.

If the power transmitted in harmonic components of the $60-\mathrm{Hz}$ supply is large enough, wave shape distortion of the types illustrated in Figures $4 \mathrm{~d}$ and 5 can cause power quality problems with some equipment. Adverse effects of harmonics are equipment malfunctions or failures as result of overvoltage, excess heating, inadvertent switching and/or relay operation, or improper power frequencyregulated functions, such as motor speed. As discussed before, harmonics can also be generated and transmitted to adjacent equipment at frequencies characteristic of power electronic devices, including converters, inverters, rectifiers and switching power supplies. 


\subsection{Customer Control of P ower Q uality and R eliability}

Many instances of poor PQ and PR originate on the customer's side of the meter. Anecdotal evidence presented and discussed at various past symposia of the power industry indicated that up to $90 \%$ of poor PQ reported in the 1980s was the fault of the customer or the electrical system within his/her facility. The source of poor PQ prior to 1980 often led to disputes and litigation to determine responsibility. As PQtolerant equipment was introduced, this conflict moderated. However, because there may now be an escalating sensitivity of some new digital electronics and other equipment to previously tolerated electrical disturbances, the issue of the practices and actions of the customer on its side of the meter is again coming under scrutiny.

Whether or not good quality power is supplied by the utility, the condition of the wiring, equipment and protective devices on the customer's side of the meter can have an important bearing on the actual PQ experience of the end user. Many common practices and ordinary issues neglected by the consumer result in poor PQ and PR. Furthermore, many of the most cost-effective PQ and PR improvements can be made on the customer's side of the meter.

This section briefly reviews the PQ and PR experience that can be influenced by various practices of and actions controlled by the end user.

\subsection{Equipment Additions}

A common consumer practice is to add electrical equipment incrementally over time without regard for the adequacy of the facility's basic wiring and electrical protection systems. Unless such additions require the approval of licensed inspectors, who could be expected to disapprove such practice, the accumulation of load in any facility tends eventually to challenge the rated current-carrying capacity of the service connection and facility wiring. The tendency to overload circuits in this manner is a common reason the customer complains of poor PQ and PR. Typical experience in this case includes excessive voltage drops and power lost to resistive heating in building circuits, and enhanced interference between various loads. In an extreme case, the consumer may overload the service and wiring capacity to an extent that causes a local "brown-out" within the facility, thereby degrading the performance and reliability of most electrical loads in the building.

Large motors and other loads that draw reactive power (i.e., energy flowing in quadrature to the "real power" that is absorbed by a purely resistive load) decrease the power factor of a facility. This results in the facility as a whole drawing much larger phase currents than would otherwise supply the same power to resistive loads. Uncompensated reactive loads that are added by the end user without regard for the adequacy of power distribution within a facility can cause similar PQ problems as described above.

\subsection{In-Facility Distribution System Integrity}

It is fairly typical for the utility customer (ranging from homes to businesses and small industries) to continuously upgrade and/or add electrical appliances in a facility that has an old or aging internal power distribution system. The customer may be unaware of aging effects until they become suddenly obvious, and also may not maintain the system in conformity with up-to-date electrical codes and standards. Aging can gradually degrade a system and eventually cause internal PQ problems. For example, agerelated corrosion can reduce the quality of bonded connections and result in the generation of heat and even intermittent conduction that could be a source of electrical noise. Deteriorated insulation can produce similar PQ effects, as well as increasing the ris k of short circuits, electrical shocks to personnel, and fires. 
The integrity of grounding connections is similarly important from a safety and PQ management perspective. Deteriorated or faulty grounding can cause dangerous and potentially damaging voltages and electric charge accumulations, which are also sources of poor PQ. Proper grounding (and the avoidance of ground loops) according to modern standards of good practice is critical insurance against equipment damage and personal injury when equipment malfunctions occur.

In general, the majority of poor PQ and PR that originates on the customer side of the meter can be traced to deficiencies in the adequacy and/or integrity of in-house electrical distribution and protection systems. If these systems do not conform to modern electrical codes and standards, a customer's poor PQ and PR may well be self-inflicted. 


\subsection{P ower Q uality Solutions}

A significant challenge the consumer faces is how to optimally protect high-value equipment and production lines from the consequences of poor PQ. From the most fundamental perspective, PQ management is an insurance issue. The principal point of contention revolves around the question "who is going to pay the insurance premium?" In fact, many grid customers do simply that ? pay premiums on policies issued by insurance companies to cover the losses incurred by poor PQ. Presumably, this practice is, or until recently was, cheaper than the self-insurance provided by installing appropriate protective equipment. A present trend is a rapidly increasing insurance claim rate (see Figure 1) as PQrelated losses escalate. This situation may eventually evolve into one in which insurance premiums are more expensive than the acquisition of protective equipment. An even more extreme result may be that underwriters no longer offer PQ insurance of any kind.

Many do-it-yourself options are available to power consumers who cannot buy insurance or persuade utilities and/or the appropriate regulatory bodies to provide improved PQ on the supply side. This section provides a quick overview of protection strategies and the major classes of equipment that offer the consumer various levels of PQ protection.

\subsection{Protection Strategies And Planning}

The consumer's first consideration is which supply-side disturbances are tolerable and which are not. The disturbance categories illustrated in Figure 4 typically do not occur at the same frequency, nor are most utility customers generally vulnerable to all types of poor PQ. Figure 8 represents a typical disturbance frequency in 100 consecutive events. In this example, voltage sags are by far the most frequent disturbance encountered.

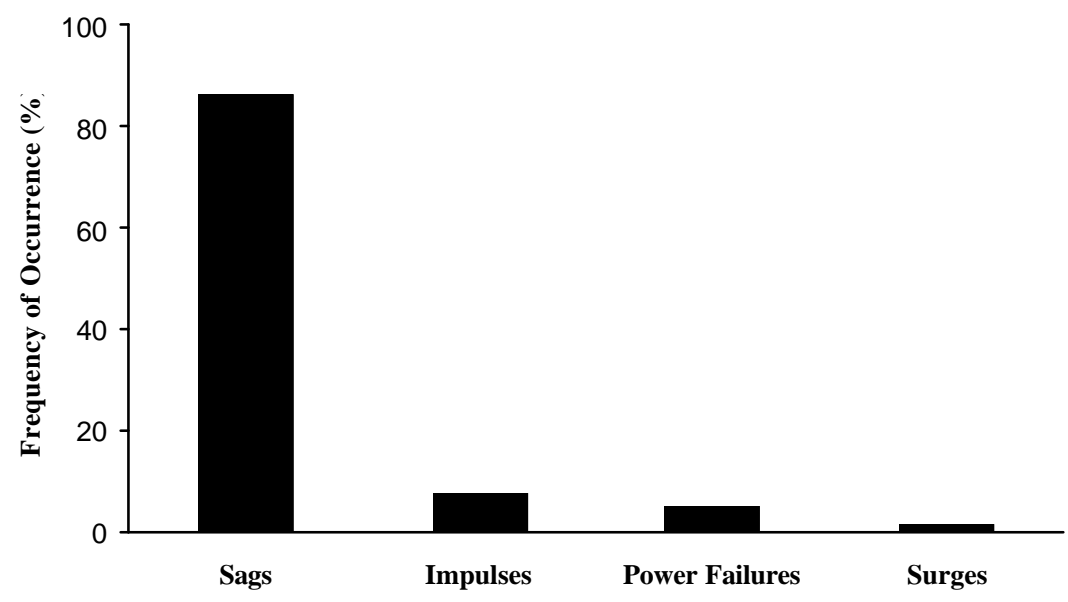

Figure 8. Representative Distribution of 100 Consecutive PQ Events

It is both essentially impossible and prohibitively expensive to plan for $100 \%$ protection (even insurance compensation is reduced by deductibles). An optimum approach for the individual is to tailor costeffective protection based on specific vulnerabilities, the dominant PQ problem(s) experienced, and the 
corresponding cost of poor PQ. Before taking independent action, the consumer should seek advice from and/or negotiate with the utility that provides the electrical service. Some disturbances may turn out to be controllable by relatively simple changes in standard operating procedures. For example, the utility may be amenable to changing the settings of voltage regulation equipment or rescheduling aspects of system maintenance to solve commonly experienced PQ problems. This is particularly true of vegetation control, where trees that grow rapidly and make momentary line contact during windy weather can sometimes account for the majority of the voltage sags on a feeder in the vicinity.

\subsection{PQ Tolerant Equipment}

As discussed above, many end users discover their PQ vulnerabilities as an afterthought. While the media has addressed the overall PQ issue for several years now, it is time that consumers are pro-active in anticipating the PQ sensitivities of equipment about to be acquired. If affordable, the best PQ strategy would be to purchase electrical equipment that is engineered to be insensitive to the supply-side disturbances prevalent at the user's location. A lot of equipment of this type is already available. For example, many common personal computers and power electronic systems can be plugged in directly to any $50-\mathrm{Hz}$ or $60-\mathrm{Hz}$ AC source with supply voltage ranging from $90 \mathrm{~V}$ to $250 \mathrm{~V}$. Such a unit should be immune to common voltage sags and frequency distortion, but could still possibly need protection from surges. Thus, equipment selection in advance can be an important part of limiting the range of anticipated PQ problems and reducing the cost of protection.

Nevertheless, pre-selection of end-use components will not currently solve all PQ issues. Some electrical equipment will inevitably be PQ-sensitive and necessitate the installation of protective hardware. Some disturbances are basically transient (momentary outages, voltages sags and swells, and frequency distortion, Figures 4a, 4b, 4c and 4f, respectively). Others are persistent (indefinite outages (PR)), harmonic distortion, commutation notches, surges and electrical noise, Figures $4 \mathrm{a}, 4 \mathrm{~d}, 4 \mathrm{e}, 4 \mathrm{~g}$ and $4 \mathrm{~h}$, respectively). These two groups provide a general means of classifying the mitigation approaches discussed below.

\subsection{Transient Protection}

The function of transient protection devices is to detect significant voltage and frequency deviations as rapidly as possible and to immediately supply the make-up energy needed to sustain an operation during a supply-side disturbance. The make-up energy is the energy that the utility fails to deliver during the transient. Protection equipment of this general type is known as a "carry-through" or "ride-through" device.

The size and complexity of devices performing this task range over several orders of magnitude, depending on the amount of energy that must be supplied and the required response time. A critical challenge is to detect the supply deviation and provide carry-through power before PQ-sensitive equipment trips off line under the control of other forms of protection, such as voltage and/or frequency sensitive relays. This typically requires electronic logic that first decides whether the incoming power wave is of adequate quality. When a "glitch" is detected, the microprocessor causes electrical energy to be released from some form of storage medium (e.g., a battery) to carry the load through the disturbance.

There is a substantial volume of equipment of this type already marketed and supported by many vendors (Power Quality Assurance, 2001). Complexity and expense rise with the energy demand of the protected process. In addition, it becomes more difficult to deliver this energy fast enough to preempt the action of conventional relay protection. 
Thus, small appliances and low energy processes can be protected by relatively simple battery-powered systems, while motor-generator sets equipped with flywheels protect processes of intermediate size and value. SMES devices have also been developed to provide protection in the high-power, fast-response market niche. Such devices can supply up to several megajoules (millions of watt-seconds) of energy with a detection/response time of about $4 \mathrm{~ms}$ or $1 / 4$ th of a $60-\mathrm{Hz}$ power cycle. Costing several hundred thousands to millions of dollars, such units have potential application where the unit cost is comparable to the value of damage and lost production avoided with only a few successful carry-through actions. Microchip manufacturing is an example of an industry that faces losses of this general magnitude as a result of momentary supply outages.

\subsection{Protection Against Persistent Phenomena}

The category of equipment known as UPS provides protection from supply-side PQ and PR problems of both the transient and persistent nature. A principal distinction between the two modes of operation is whether the carry-through device activates by sensing each disturbance when it occurs (transient protection) or operates continuously as a virtual (or actual) "flywheel." Once again, it is important to note that combating harmonic distortion, surges and electrical noise requires less sophisticated passive equipment, such as filtering and voltage-limiting devices.

There is a very wide range in the performance, complexity, operating mode and cost of UPS. For example, some battery-based systems operate in the PQ and PR protection modes continuously. In this mode, the load is driven through a power conditioning system (inverter) directly from the battery that, in turn, is continuously recharged by the grid supply. The battery charging circuit can be designed to be insensitive to all the disturbance types shown in Figure 4. The battery supplies essentially constant voltage to the inverter and the load sees perfect power quality, unless an outage lasts longer than the battery's load-carrying capacity or the battery fails for other reasons. Battery-based systems are also designed to carry important loads until hydrocarbon-fueled generators take over.

However, battery-based systems have disadvantages (including battery life, weight and hydrogen gas emissions) and are not considered to be a general panacea for PQ and PR problems. Competing systems include some emerging technologies such as vacuum-contained flywheels and even fuel cells. As both the value of PQ and PR protection escalates and the capabilities of the technology advance, these solutions are expected to find more pervasive use.

The above review mentions just a few examples of the many options and combinations that are commercially available. The recent comprehensive summary of products and services that provide PQ protection in "2002 Buyers Guide”, published by Power Quality Assurance® Magazine (Power Quality Assurance, 2001), is recommended for further reference.

\subsection{Power Quality and Power Reliability Management In The Future}

It has been suggested that, in the future, improved power supply reliability and quality may result from the anticipated deployment of advanced technology broadly categorized as DER, located both throughout the distribution grid and at homes, commercial buildings and so on. The essence of the project work is to assess the ability of existing, under development, and proposed DER systems, grid integration methods and DER control methods to capture the maximum reliability and power quality benefits. 
As discussed, DER is expected to be based on generation and storage technologies that serve as either primary (generation technologies) or backup power supply systems. The UPS ("carry-through") function may be provided by systems that include storage devices, such as flywheels, advanced battery systems, supercapacitors, and SMES. DER is expected to be based on systems such as microturbines, fuel cells, diesel generators, and solar and wind power generator arrays. Hybrid combinations of these systems, such as packaged diesel/wind generators with battery backup are also anticipated. 


\subsection{Conclusions}

Growing electricity power supply reliability and quality problems are having an increasing financial impact on business and industry in the United States. The impact is most pronounced within the digital landscape, where companies that rely upon high-speed electronics and computer-based operations and communications suffer serious losses whenever there is a significant PQ loss or deviation. As protection against the consequences of poor PQ reduces to a cost-of-insurance issue, the challenge facing the individual facility operator is to acquire the least-cost protection commensurate with the risk and cost of potential losses.

While a broad range of PQ management options is already available, the current climate of increasing PQ sensitivity and value are incentives for the development of the better, more cost-effective solutions for the future. Both new technologies and changes in utility system organization and operations may provide a number of solutions. The financial impacts of less than adequate power quality and reliability and the consequent demand for solutions, coupled with the unique characteristics of distributed energy resources offer an opportunity for more rapid deployment of DER. The deployment of such systems would provide both primary and backup power supplies to overcome utility and site-specific supply problems, and to help compensate for the supply quality limitations of the existing distribution grid. 



\subsection{References}

ANSI. 1995. American National Standard for Electric Power Systems and Equipment-Voltage ratings (60 Hertz), ANSI C 84.1-1995. Published by the National Electrical Manufacturers Association, Rosslyn, Virginia.

Barker, P. P. and R. W. de Mello. 2000. "Determining the Impact of Distributed Generation on Power Systems: Part 1 - Radial Distribution Systems." Presented at the IEEE PES Summer Power Meeting, Seattle, Washington.

DeWinkel, Carel and Jeffrey D. Lamoree. 1993. "Storing Power for Critical Loads", IEEE Spectrum, June 1993.

Brown, E. R. 1998. "Megawatt Solid-State Electronics", [http://www.darpa.mil/MTO/HPPS/1998MgWts.html] web page. Reviewed 1-16-02.

Hawaiian Electric Company, Honolulu, Hawaii. 2001. [http://www.heco.com/cda/frontdoor/] web page. Reviewed 11-17-01.

IEEE. 1992. IEEE Recommended Practices and Requirements for Harmonic Control in Electric Power Systems, IEEE Standard 519 -1992. Published by the Institute of Electrical and Electronic Engineers, Inc., New York.

IEEE Gold Book. 1997. IEEE Recommended Practice for the Design of Reliable Industrial and Commercial Power Systems, IEEE Standard 493-1997. Published by the Institute of Electrical and Electronic Engineers, Inc., New York.

IEEE Gold Book. 1980. IEEE Recommended Practice for the Design of Reliable Industrial and Commercial Power Systems, ANSI/IEEE Standard 493-1980. Published by the Institute of Electrical and Electronic Engineers, Inc., New York.

MIRUS International Inc. 1994. "Designing Modern Electrical Systems with Transformers that Inherently Reduce Harmonic Distortion in a PC-Rich Environment.” In Power Quality Proceedings, September 1994, pp. 167-178.

Power Quality Assurance. 2001. Power Quality Assurance® Magazine, 2002 Buyers Guide in December 2001 Issue. Published by PRIMEDIA Business Magazines \& Media Inc., Overland Park, Kansas.

U.S. Department of Commerce, National Bureau of Standards. 1983. In Federal Information Processing Standards Publication 94, "Guideline on Electrical Power for ADP Installations," September 21, 1983.

Willis, H. Lee and Walter G. Scott. 2000. Distributed Power Generation: Planning and Evaluation, Published by Marcel Dekker, Inc., New York.

Yeager, Kurt E. 2001. "Electricity Technology Development for a Sustainable World: Bridging the Digital Divide." World Energy Council $18^{\text {th }}$ Congress, Buenos Aires, Argentina, October 21-25. [http://www.epri.com/corporate/discover_epri/news/HotTopics/WorldEnergyCouncil.pdf] web page. 



\section{APPENDIX A}

An Overview of DC to AC Electric Power Converters 



\section{Appendix A: An O verview of DC to AC Electric Power Converters}

The conversion of electrical power from direct current $[\mathrm{DC}]$ to alternating current $[\mathrm{AC}]$ has always presented significant challenges to engineers. At one time, the preferred way to accomplish it was using bulky, inefficient rotating machines. However, the advent of semiconductors and power electronics led to the development of solid-state DC to AC electric power converters - also known as "inverters." These devices, composed primarily of electronic switches, can be divided into two classes ? line-commutated and force-commutated, distinguishable as follows:

- Line-commutated inverters switch in response to voltage changes in the system to which they are connected. The dependency on an external signal restricts their control over the delivered power and prevents them from operating independently. They are cheaper and less complex than forcecommutated converters and, therefore, are widely used in less demanding applications.

- Applications that demand a high degree of power control usually require a force-commutated inverter. The electronic switches in this class of inverter are actuated by a built-in logic circuit. This permits the inverter output to be controlled independently of the system to which it is connected.

Pure AC power is characterized by sinusoidal voltage and current waveforms. These waveforms are produced and absorbed naturally by rotating electric machines and offer advantages in power transmission, such as the ability to easily and efficiently transform power to high voltage for transmission and distribution or low voltage for consumption. Electronic power converters, such as the pulse width modulation type [PWM] and step wave power converter type [SWPC] cannot naturally produce sinusoids. Their digital nature means that they can only produce voltage and current pulses or steps, and not the pure sinusoid required by AC circuits. Consequently, these DC to AC converters only approximate the desired output.

IEEE Standard 519-1992 clearly defines power quality criteria for determining whether a converter's sinusoid approximation is "close enough" to a true sinusoid to allow it to be interconnected with other AC equipment. Particular attention is paid to avoiding harmonics. (Harmonics are sinusoids with frequencies that are multiples of the base electrical frequency. When present, they can seriously damage rotating electrical equipment and sensitive electronics.) Each of the DC to AC converter types described below uses a different method of approximating a sinusoid.

The PWM power converter approximates a sine wave by emitting a series of high frequency pulses. Varying the ratio of the amount of time the output is "high" to the amount of time the output is "low" controls the width of these pulses. Application of this output to a low pass filter produces an approximation to the sinusoid by taking a type of moving average. In this case, the harmonics are attenuated during the filtering process. This method of creating AC power from DC power has been used for over 20 years and works very well if the pulses are fast enough (several thousand pulses per electrical cycle) and the output is filtered properly. It is, however, limited to one source per converter and requires an external transformer if the voltage needs to be stepped up.

The SWPC approximates a sinusoid by adding voltages from one or more sources. The inputs are switched on and off under microprocessor control so that the sum of their voltages tracks the desired output. Although the number of sources the SWPC can accept is theoretically unlimited, each additional source connected increases the complexity of the control system, as well as the number of components required. 
